\title{
Sistemas terapêuticos
}

e formas de libertação controlada, de uso não parentérico*

A. Lupi Nogueira a

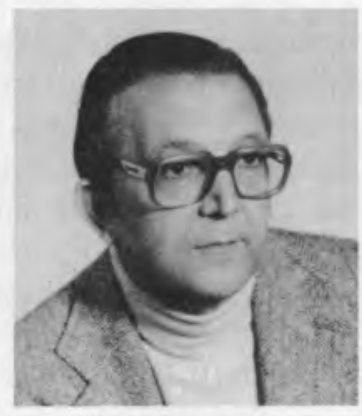

A. Lupi Nogueira

Nasceu em Lisboa, em 8 de Julho de 1921.

É Professor Associado Definitivo do 3. Grupo (Ciências Farmacêuticas) da Faculdade de Farmácia de Lisboa.

Iniciou a sua vida profissional como analista na Comissão Reguladora dos Produtos Químicos e Farmacêuticos (1946-1952). Por convite assume a Dir. Técnica do Laboratório Fidelis (1952-1954). Igualmente por convite, transita para a Dir. Técnica do Lab. Medicamenta (1954-1962). Director de Produçâo e do departamento de pesquisa e desenvolvimento do Lab. Sanitas (1962-1980). Interessado na carreira académica ingressa como assistente voluntário da Escola de Farmácia de Lisboa (1952-1954) sendo então contratado como 2.-assistente de Galénica e de Técnica Farmacêutica (1954-1960). A fim de poder concluir os trabalhos para doutoramento passa novamente a assistente voluntário (19601965). Conclui as provas de doutoramento em Maio de 1965 com 18 valores. Segue-se um interregno na carreira académica até 1975, altura em que é contratado como equiparado a professor extraordinário passando ao quadro por nomeaçâo como professor associado com efeitos a partir de 1979. Após a apreciação elogiosa do seu relatório quinquenal é nomeado a título definitivo (1984).

Colaborou activamente na Organizaçẫo do 2.․ Congresso Luso-Espanhol de Farmácia, bem como nas 7.as Jornadas Farmacêuticas realizadas em Lisboa, Porto e Coimbra.

Foi membro da Comissão Permanente da Farmacopeia Portuguesa. É membro da Comissão para o Formulário Nacional de Medicamentos e da Comissão Interuniversitária para a Reforma do ensino de farmácia (1985-1986). Desde 1975 tem colaborado em todos os órgãos de gestão da Faculdade de Farmácia de Lisboa.

É membro da British Society of Rheology (1973).

Tem publicados mais de trinta artigos e proferiu numerosas conferências.

\section{Conceitos Gerais}

A administração peroral duma dose única dum fármaco é traduzida por uma curva concentração plasmática/tempo, dependente da absorção, distribuição, metabolismo e eliminação (ADME) de configuração clássica e característica. A curva ascende rapidamente, atinge um máximo e cai exponencialmente. No pico de concentração máxima, a velocidade de absorção iguala a de eliminação.

Se fizéssemos a ministração de nova dose de fármaco apenas quando o ramo descendente da curva se aproxima da concentração inicial, a curva repetir-se-ia de maneira similar, dando origem a um intervalo de tempo, sem qualquer actividade terapêutica, excessivamente longo, com todos os inconvenientes que daí advêm.

Se, pelo contrário, fizermos novas tomadas medicamentosas logo que a concentração plasmática atinja o nível terapêutico mínimo, no ramo descendente, conseguimos manter uma actividade terapêutica durante muito mais tempo, apesar da existência de picos e vales pouco desejáveis. Numa hipótese destas, o doente teria de ser incomodado numerosas vezes durante as 24 horas, com a inevitável tendência à não obediência ao esquema posológico (sempre que o intervalo entre cada dose seja infeorior a 8 horas, a «desobediência» aumenta).

Por vezes a dose do fármaco tem de ser excepcionalmente elevada, ultrapassando o limite tóxico, para que haja concentração activa no local onde é pedida a sua acção. Daí os inevitáveis e indesejáveis efeitos colaterais ou secundários. Poderemos, em resumo, referir os principais inconvenientes das formas galénicas convencionais do seguinte modo:

- Duração de acção do(s) princípo(s) activo(s), por vezes muito breve.

- Necessidade de várias administrações durante o dia para melhor aproveitamento das concentrações com actividade terapêutica.

- Grandes flutuações de níveis plasmáticos, em especial com as formas orais.

- Necessidade de elevadas concentrações para obter suficiente princípio activo ao nível do local de acção.

- Efeito da primeira passagem hepática, particularmente notável nas formas orais.

\footnotetext{
* Resumo alargado da palestra realizada na "Ordem dos Farmacêuticos", subordinada ao título "Sistemas Terapêuticos e novos fármacos no século XXI" (1988).

a Faculdade de Farmácia, Av. das Forças Armadas, 1600 Lisboa.
} 
- Agressividade de certos princípios activos em algumas mucosas ou órgãos.

Daí as tentativas para melhorar a actividade terapêutica segundo estratégias baseadas em métodos fisiológicos, físico-químicos ou de tecnologia farmacêutica, capazes de modificar os factores que influem na biodisponibilidade e que esquematizamos do seguinte modo:

QUADRO 1

Factores que interferem na biodisponibilidade

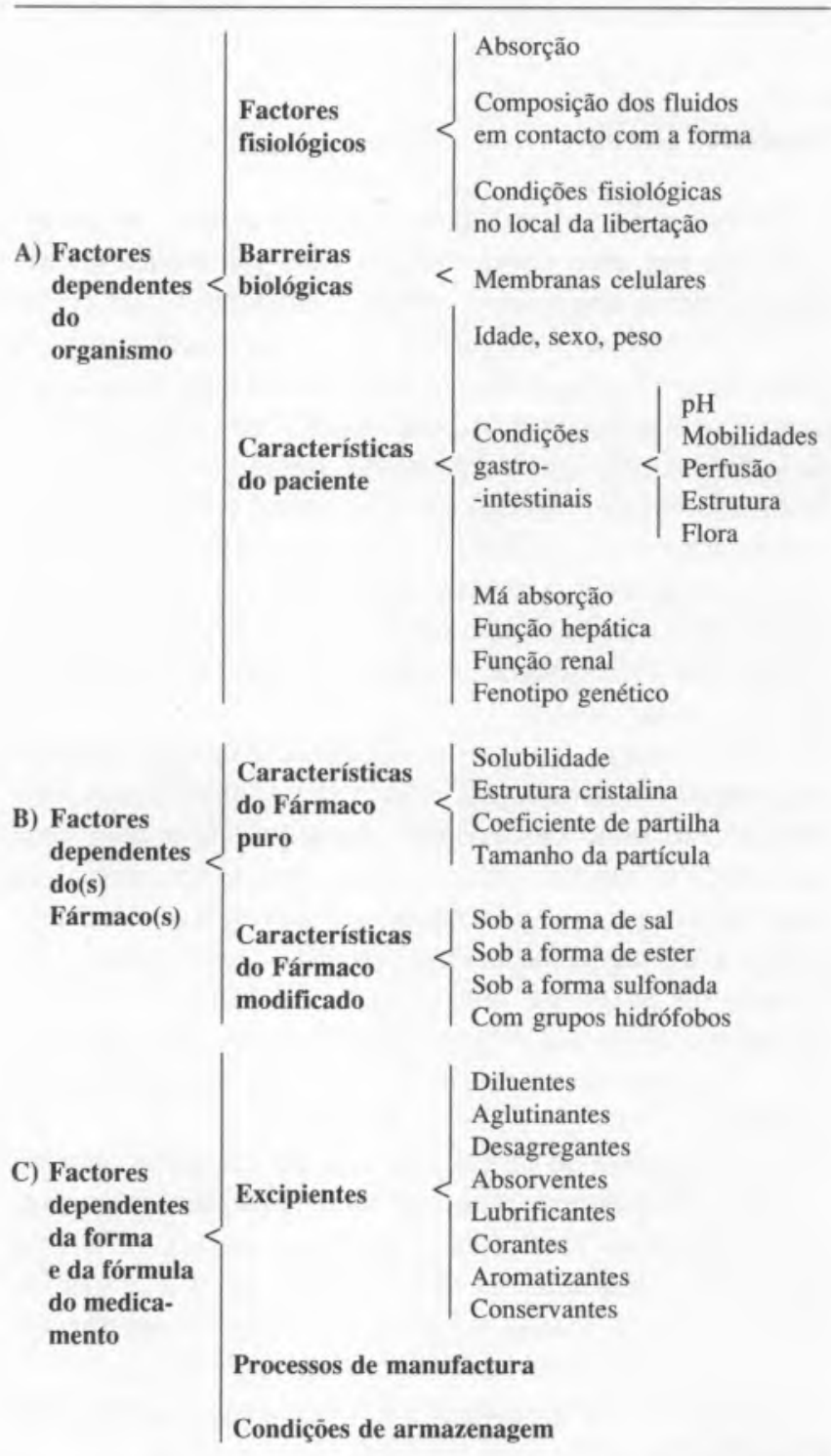

Actuando sobre tais factores é possível melhorar a absorção ou prolongar e manter a acção terapêutica.

Em todas as formas farmacêuticas tradicionais e sistémicas com excepção das administradas por via intravenosa, a cinética de absorção/eliminação segue uma reacção de ordem 2.

Sabe-se que a distribuição do fármaco no organismo só atinge o equilíbrio quando a velocidade de absorção iguala a velocidade de eliminação durante um grande intervalo de tempo (com algumas excepções - por exemplo com o antibióticos em que a concentração máxima só interessa na ocasião em que os microrganismos se multiplicam).

Ora este «desideratum», improvável com as formas galé- nicas convencionais, constitui a finalidade de todos os sistemas de libertação programada e controlada.

\section{Conceito e características dos sistemas terapêuticos}

\section{Finalidades e vantagens}

Zaffaroni, um dos principais investigadores e impulsionadores das tecnologias dos sistemas terapêuticos, era de opinião de que, em vez de se gastarem verdadeiras fortunas na síntese de novas moléculas com utilização terapêutica, se aplicassem verbas em investigação para melhoria dos medicamentos já existentes, controlando o lugar, a intensidade e a duração da acção dos fármacos que os compunham, sendo de destacar a importância da especificidade do local de absorção (o que levanta enormes problemas técnicos).

Segundo aquele investigador, um sistema terapêutico será: «dispositivo que cede um ou mais fármacos de modo contínuo, segundo um esquema predestinado, por um período fixado, quer na corrente sistémica, quer no órgão alvo».

Higuchi, resume assim as finalidades dos sistemas terapêuticos:

- Assegurar a manutenção constante e a longo prazo da actividade terapêutica, segundo uma cinética controlável (ordem 0 ou 1), reduzindo ao mínimo a intervenção do doente e proporcionando uma fácil obediência ao esquema posológico.

- Dirigir as substâncias activas libertadas, de modo selectivo, até a um alvo (órgão, célula ou tecido), com um mínimo de efeitos indesejáveis.

De qualquer forma os sistemas de libertação programada e controlada oferecem vantagens nítidas sobre as formas farmacêticas tradicionais, especialmente nos seguintes aspectos:

- Possibilitar o uso de princípios activos com semi-vida biológica muito curta.

- eliminar as grandes flutuações nas concentrações plasmáticas evitando os picos tóxicos e os vales subterapêuticos.

- Evitar os riscos de uma não obediência do paciente ao esquema posológico instituído.

- Suprimir ou diminuir acentuadamente os efeitos secundários.

- Melhorar a comodidade do doente, evitando a necessidade do despertar em pleno sono.

- Economizar, por melhor aproveitamento do princípio activo, ou pela diminuição dos custos de enfermagem.

Isto não significa que estas novas formas de libertação modificada sejam destituídas de possíveis inconvenientes. $\mathrm{Na}$ verdade pode haver:

- Risco de acumulação.

- Dificuldade de eliminação rápida em caso de intolerância. - Alguma falta de reprodutividade na resposta terapêutica (formas orais).

- Modificação do programa por fraccionamento das formas sólidas.

- Perda de flexibilidade nas dosagens individuais.

\section{Elementos constituintes de um sistema terapêutico}

Entre os quatro elementos que compõem um sistema (o fármaco, o módulo de libertação, a plataforma e o programa terapêutico), talvez possamos considerar como mais impor- 
tante a unidade que controla a libertação do fármaco, já que terá de possuir um reservatório, um elemento de controlo de libertação, uma fonte de energia e uma abertura ou superfície de libertação.

O papel dos polímeros sintéticos na unidade do controlo de libertação é de tal importância que reside neles a base da maioria das patentes registadas.

A plataforma, que integra o conjunto de elementos do sistema, ou é móvel dentro de determinada zona (via oral), ou adere ao local de administração (transdérmicos).

\section{Sistemas orais de libertação controlada}

O facto da via oral ser a mais fisiológica, justifica que um grande número destes sistemas tenha sido orientado para o aproveitamento desta via, ainda que, ironicamente, seja aquela que apresenta maior número de problemas não resolvidos, e que só terão resposta cabal depois do perfeito domínio dos fenómenos intra-celulares no tracto gastro-intestinal, a nível da biologia molecular. Quando, para os sistemas orais em particular, for dominada a tecnologia que permita uma libertação do princípio activo em local específico, estaremos na presença de medicamentos para «depois de amanhã».

Pela sua enorme superfície o tracto digestivo será uma região que, potencialmente, pode permitir grande e selectiva absorção. Porém, um dos condicionalismos a vencer será o da motilidade, que tentará remover tudo o que não for endógeno. Já é de há muito conhecido que o peristaltismo é diferente na situação de jejum ou com o estômago cheio.

Por isso, os principais desafios postos aos investigadores, foram o de controlar o tempo de trânsito intestinal e o de evitar ou diminuir a eliminação pré-sistémica.

Isto justifica que tenhamos tentado agrupar alguns desses sistemas em cerca de 5 sub-grupos e respectivas variedades.

\section{Dispositivos flutuantes}

Em teoria, para aumentar o tempo de trânsito intestinal basta reter ou fixar o sistema a qualquer área do tracto gastro-intestinal. Assim, algumas das patentes de sistemas baseiam-se no maior tempo de permanência no estômago. Para tal, as tecnologias utilizadas conseguem que os sistemas boiem no suco gástrico por obtenção de densidades inferiores a 1 .

\section{a) Com hidrocolóides}

A granulação do fármaco com hidrogeles (como a hidroxietilcelulose, hidroxipropilcelulose, hidroxipropilmetilcelulose, carboximetilcelulose sódica, em proporções variando de 20 a $75 \%$ ) e posterior compressão a uma dureza de $7 \mathrm{Kp}$, permite a otenção de comprimidos, que em contacto com o fluido gástrico gelificam à volta do comprimido, formando uma barreira insolúvel e tornando-os menos densos que a água (U.S. Patente 4.167.558 e 4.140.755).

b) Dispositivos insufláveis

Em patentes mais sofisticadas, em que a plataforma do sistema é uma cápsula de gelatina, existe uma câmara con- tendo um líquido que se vaporiza à temperatura do corpo e que insufla a respectiva câmara, fazendo boiar o conjunto. Essa câmara é posteriormente colapsada pela dissolução gradual dum filamento dum polímero biocompatível, sendo então ejectado o reservatório contendo o princípio activo que será libertado por difusão através da membrana polimérica (U.S. Patente 3.901.232).

Numa variante deste processo, para além dum suporte igualmente insuflável que obriga o conjunto a boiar, a libertação do fármaco a partir do dispositivo é controlada por pressão osmótica (U.S. Patente 3.786.816).

\section{Bombas osmóticas}

Foram patenteadas inicialmente pela Alza Corpporation, através dos estudos de Zaffaroni, Higuchi e outros com a designação de sistemas OROS e OROS push-pull (OR de oral e $O S$ de osmóticos).

No $1 .^{\circ}$ caso o núcleo do comprimido é envolvido numa membrana semipermeável apenas interrompida por um pequeno orifício conseguido com raios laser. Ao contacto com o suco gástrico só entra água para o núcelo do comprimido, criando pressão osmótica suficiente para fazer sair produto pelo orifício em velocidade constante, igual à velocidade de entrada de água. A cinética de libertação será portanto de ordem zero, independente da quantidade de fármaco que permanece no comprimido e que deve manter-se constante em função do tempo (U.S. Patente 4.036.227).

$\mathrm{K}_{\mathrm{L}}{ }^{\circ}=$ velocidade de entrada de água = velocidade de saída do fármaco=Ke.Cd.Vd.

$\mathrm{K}_{\mathrm{L}}{ }^{\circ}$ - Constante de velocidade de ordem zero do fármaco

$\mathrm{Ke}$ - Constante de velocidade de ordem um para administração global do fármaco

Cd - Nível do fármaco desejado no corpo (quantidade/ /volume)

Vd - Volume do espaço onde se distribui o fármaco

Lonsdale utiliza a seguinte equação:

$$
\frac{\mathrm{dv}}{\mathrm{dt}}=\mathrm{K} \frac{\mathrm{A}}{1}(\Delta \pi-\Delta \mathrm{P})
$$

$\frac{\mathrm{dv}}{\mathrm{dt}}$ - velocidade do fluxo de água

$\Delta \pi$ - diferença em pressão osmótica

$\Delta \mathrm{P}$ - diferença em pressão hidrostática

$\mathrm{K}$ - permeabilidade da membrana (área)

A - superfície da membrana (área)

1 - densidade da membrana

Na variante «push-pull», a fonte de energia é também a pressão osmótica, não provocada pelo produto activo, mas por uma substância osmoticamente activa, como o cloreto de sódio ou o cloreto de potássio, contida num compartimento, parcialmente envolvido por uma membrana semi-permeável, obstruído na parte restante por uma membrana elástica impermeável, que vai sendo deformada à medida que a água entra no compartimento osmótico. Como consequência dessa deformação o produto medicamentoso sai pelo orifício feito 
por laser, também em velocidade constante (cinética de ordem zero).

Este dispositivo não obriga a fármacos osmoticamente activos, além de permitir o uso de líquidos ou pastas no compartimento contendo o princípio activo (G.B. Patente 1.551.898).

\section{Sistemas orais controlados por difusão}

Nestes sistemas a velocidade de libertação do fármaco é dada pela sua difusão através de um polímero insolúvel na água. Existem dois tipos fundamentais: um em que o fármaco está num depósito central, envolvido por uma membrana polimérica e outro em que o fármaco é dissolvido ou disperso uniformemente numa matriz polimérica inerte.

Os sistemas reservatórios são controlados pela aplicação da 1. ${ }^{\mathrm{a}}$ lei de difusão de Fick.

$$
\mathrm{J}=-\mathrm{D} \mathrm{dCm} / \mathrm{dx}
$$

$\mathrm{J}=$ fluxo do fármaco através da membrana

$\mathrm{D}=$ coeficiente de difusão do fármaco nas membranas

$\mathrm{dCm} / \mathrm{dx}=$ gradiente de concentração do fármaco

Algumas das patentes registadas para sistemas controlados por difusão constituem variantes deste fundamento.

\section{a) Com membranas microporosas}

O comprimido é envolvido por um polímero não degradável pelo meio gástrico (co-polímero de cloreto de vinilo e acetato de vinilo misturado com uma pequena quantidade de substâncias solúveis (lauril-sulfato de sódio). Em contacto com o fluido gástrico desparece a substância solúvel, ficando uma membrana microporosa. A rigidez e tamanho do poro são evidentemente reguláveis (N.L. Patente 7.313.696).

\section{b) Membranas de solubilidade controlável}

O comprimido é envolvido por um polímero termoplástico do tipo do cloreto de polivinilo, misturado com um plastificante como o ftalato de dioctilo. Este último vai criar uma solubilidade controlada da membrana no fluido gástrico (B.E. Patente 814.491).

c) Com resinas de troca-iónica

A adsorção do fármaco a grânulos de resina de troca-iónica dá origem a um complexo que por sua vez pode ser ou não envolvido por um polímero permeável à água (co-polímero do ester poliacrílico-metacrílico). Da proporção de grânulos envolvidos e não envolvidos resultarão diferentes velocidades de libertação do fármaco, independentemente do ambiente gástrico ( $\mathrm{pH}$, acção enzimática, esvaziamento, etc.) - U.S. Patente 4.221.778.

\section{Sistemas muco-adesivas}

Atendendo a fármacos que sofrem extenso metabolismo de primeira passagem, tem havido várias tentativas para o minimizar.
Surgem assim os sistemas mucoadesivos que utilizam polímeros capazes de se ligarem às glicoproteínas, principais componentes dos mucos subjacentes ao epitélio de cada mucosa.

É evidente que a escolha do polímero dependerá das características de cada mucina.

Dado que tais características variam ao longo de todo o tracto digestivo, em teoria, será possível fixar o sistema ao local que desejarmos (G.B. Patent 1.279.214 e U.S. Patent 3.911.099). Então as vantagens dum tal sistema seriam:

- Circunscrever os processos de «clarificação» que ocorrem no epitélio;

- Reduzir as flutuações dos níveis plasmáticos do fármaco; - Reduzir a variabilidade das respostas terapêuticas inter e intra grupos;

- Possibilitar o uso de melhoradores de penetração;

- Facilitar o transporte de petidos através do tecido epitelial, pelo uso, por exemplo, de inibidores de peptidases.

Uma das alternativas ao uso dos muco-adesivos é actuar sobre as fibronectinas, também conhecidas por proteína $Z$, que representam a «cola» que mantém unidas as células do epitélio.

\section{Sistemas para absorção no colon}

Tem sido tentada a absorção sistémica pelo colon, usando para isso polímeros apenas sensíveis ou degradáveis a $\mathrm{pH}$ $8-8,4$, valores muito frequentes naquela zona, embora isso não represente uma técnica segura.

Outra alternativa seria aproveitar o teor microbiano, qualitativo e quantitativo existente na zona. Sabe-se, por exemplo, que certas fibras dietéticas (de sementes de guar) são biodegradáveis por bactérias do colon. Bastaria impregnar tais fibras com fármacos, como esteróides, antibióticos, etc.

Algumas dessas bactérias são azorredutoras; daí a tentativa de administrar insulina envolvida em azopolímeros, degradáveis por azorredutores.

Existem na mucosa gastrointestinal vários factores que reduzem a possibilidade do transporte de macromoléculas intactas (inerentes à molécula, factores não imunológicos e imunológicos. Ig A; Ig G; Ig M; Ig E).

Mas existe evidência clínica da absorção de macromoléculas e, uma vez que os fármacos do futuro tendem a ser de natureza peptídica ou proteínica, há que avançar na investigação dos mecanismos que permitem tais absorções.

Tudo aponta para um papel preponderante do sistema linfático, das células $\mathrm{M}$, dos agregados de Peyer, etc.

Em vez de uma libertação constante é possível uma libertação pulsada, favorável a certos tipos de fármacos como os antibióticos, antineoplásicos, hormonas.

Tal libertação pulsada é mais fácil em dispositivos de aplicação parentérica, condicionando a libertação do fármaco a uma resposta enzimática (administração de insulina por glucose-oxidase).

\section{Sistemas transdérmicos ou percutâneos}

Entre os sistemas transmucósicos são sem dúvida os transdérmicos aqueles que parecem melhor estudados. O seu grande sucesso iniciou-se com a escopolamina, num pequeno penso que se coloca atrás da orelha, permitindo uma 
protecção contra o enjoo das viagens durante três dias, com uma libertação de ordem zero, sem os efeitos secundários acusados pela administração oral.

Mas recentemente surgiram os pensos com trinitroglicerina, cujos resultados entusiasmaram exageradamente os médicos, os doentes e os investigadores, a ponto de se pensar que qualquer fármaco poderia ser incorporado num sistema transdérmico.

Apesar das muitas vantagens que estes sistemas exibem existem também várias limitações ao seu uso generalizado.

$\mathrm{Na}$ verdade entre as vantagens situam-se:

- Redução dos problemas relacionados com o metabolismo do primeira passagem, donde o uso de doses muito baixas dos fármacos.

- Manutenção de níveis plasmáticos.

- Fácil obediência do doente.

- Remoção do sistema em qualquer altura, quando se manifestam efeitos indesejáveis.

Mas a tecnologia dos sistemas transdérmicos só é acessível a fármacos muito potentes, e difícil ou impossível para fármacos demasiado lipofílicos e fármacos ionizados (só por iontoforese). São formas potencialmente alergizantes.

Os fármacos contidos nestes pensos percutâneos podem sofrer reacções enzimáticas e serem metabolizados pela microflora local.

A tecnologia de fabrico é complicada já que envolve, numa pequena superfície, o uso de melhoradores de permeabilidade (dimetilsulfóxido, ureia, 2-pirrolidona, azona, surfactantes não iónicos) e escolha duma membrana microporosa polimérica, um reservatório do fármaco ou uma matriz polimérica.

Entre os sistemas transmucósicos nasais estuda-se com esperança fundamentada a administração de insulina.

\section{Sistemas locais}

Baseados na libertação do fármaco controlada por difusão referimos apenas o OCUSERT e o PROGESTASERT, o primeiro para o tratamento do glaucoma, por libertação constante de policarpina durante cerca de uma semana (sem o perigo e os inconvenientes do colírios clássicos), e o segundo como dispositivo intra-uterino, usado como contraceptivo, com a libertação constante de progesterona durante 180 a 360 dias.

\section{Outros sistemas}

Para não tornar excessivamente longa esta exposição, e porque noutro artigo são parcialmente tratados, não abordámos os novos sistemas terapêuticos administrados por via parentérica onde também se verificam enormes progressos tecnológico., Basta recordar os sistemas citotrópicos e o sofisticado «pâncreas artificial», onde um microprocessador colhe e analisa o sangue do diabético e depois injecta a quantidade de insulina, por dilatação dos poros da pele e acesso aos capilares subcutâneos.
Informação Riedel-de Haën:

TITULAÇÃO KARL-FISCHER

\section{HYDRANAL Titulação KF perfeita!}

HYDRANAL • é a nova geração de reagentes de Karl-Fischer isentos de piridina. Os reagentes HYDRANAL ${ }^{\circ}$ melhoraram drasticamente as características de titulação, sendo por isso usados em laboratórios de análise espalhados por todo o mundo. Estes reagentes estão patenteados mundialmente.

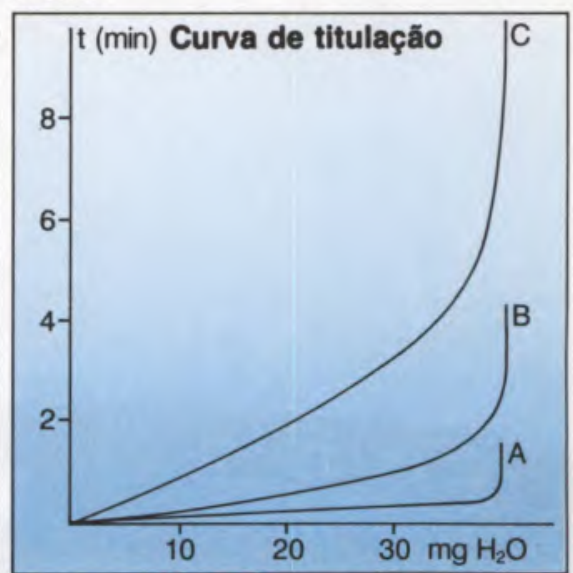

Curva A: Solvente-titulante HYDRANAL ${ }^{\circledR}$

(reagente com dois componentes)

Curva B: Compósito HYDRANAL (reagente monocomponente)

Curva C: Reagentes antigos contendo piridina

Vantagens:

- titulaçăo rápida

- ponto final estável

- resultados precisos

- isentos de piridina

- isentos de metilglicol

Riedel-de Haën

Aktiengesellschaft

Wunstorfer Str. 40

D-3016 Seelze 1

Telefon (51 37) 7 07-248

Hoechst Portuguesa S.A.

Apartado 6

Estrada Nacional - Lisboa-Sintra

Mem Martins / Portugal

Telefones (1) 9212160 / 9217723

Telex: 16380 Hoelis

Telefax: (Infotec 6510) (1) 9210010 


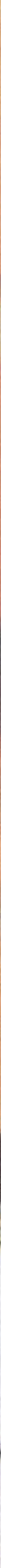

